The International Conference : Cities' Identity Through Architecture and Arts (CITAA)

\title{
Public Art Development
}

\author{
DOI: $10.21625 /$ archive.v1i1.139 \\ Hassan Ahmed Ismail 1 \\ ${ }^{1}$ BArch - Cairo University MDesR - SCI-Arc
}

\section{Keywords}

Public Art Development; Challenges among the built environment; Advertising practices; Construction industry; Urban observations; Façade colors and patterns; Organized randomness; Creative efforts and contributions; Commercial street art; Decorative concrete; Colorful bricks; Tinted bricks

\begin{abstract}
Please allow me to express my interest in participating in the event; the agenda and objective are of high significance for discussing the maturity and development of a sustainable "cultural and creative infrastructure" powered by cultural policies and practices. Involvement and lobbying for such topics is essential for the cultural and creative dynamics where creative cities attract creative people.
\end{abstract}

While navigating through a search engine and typing a name of a city, the first images to appear visualize the built environment of the city. For instance when you type Cairo into Google, you will be mainly looking at the Pyramids and built environment around the Nile in addition to the Old City of Cairo. If you type in New York you will find images of skyscrapers positioned around the natural landscape of the city, and so on and so forth.

Thus tourism depends a lot on the built environment and the touristic standard is subject to the built environment, type and quality of tenants attracting the general public and of course the natural landscape.

Arts and architecture play an important role among the built environment having both tangible and intangible economic impacts resulting from touristic attractions as well as other means; Cairo was once described as the most beautiful city in the world with the rich urban fabric and prosperity of the arts and architecture.

In a country like Egypt where segmentation between the different social levels is becoming a real threat for future generations, it is crucial to work with all stakeholders including the authorities, civil society and the general public with objectives that would aim to serve all interests and gain a positive public opinion.

\section{Introduction}

Capitalizing upon the booming real estate development industry in Egypt, public art development is a huge market especially for creative and cultural industries working towards community enrichment and place making through improving street visuals as a means of inspiration as well as creating value by exposure, interaction, understanding and appreciation of high artistic quality with an objective to connect art with people, enhance the design-build quality standards and stimulate the alternative tourism scene expanding as a model and catalyst for further artistic activity. There are many case studies for slums and informal areas that have been transformed from repellent neighborhoods into attractive touristic sites especially in Africa and Latin America where cultural operators sometimes even offer public art tours as part of the cultural experience.

Public art installations especially the contemporary ones are commonly located around main squares all over the governorates and are usually unappealing even though design and construction costs may reach a few hundred thousand pounds and sometimes even exceeding millions. Budgets are allocated and available both by the public and private sectors however the selection, commissioning and management processes face challenges dealing with 
stakeholders and administrative structures simply because of bureaucracy, ignorance and corruption. Egypt however has extreme urban settings with diverse social layers and which generates random yet fascinating outcomes, occasionally art initiatives take place but usually on a one-time basis yet maintenance of the works is rarely considered. However such art initiatives and projects gain a high popularity and create a positive atmosphere.

\section{Challenges among the built environment}

Segmentation in Egypt is becoming a major threat among social, cultural and urban contexts having extreme impacts on both the people and built environment whereas a healthy social fabric will only exist through penetrating and collaborating with such communities towards engagement and inclusivity. Poor engineering and maintenance together with urban segregation have negative impacts on the built environment creating a deteriorated brand and image of the Egyptian scene not reflecting upon the rich cultural heritage.

\subsection{Advertising practices}

Outdoor advertising highly impacts the city skyline and aesthetics, on an environmental level the excess use of large outdoor advertising structures contribute towards an unsustainable sprawl in terms of new construction including but not limited to billboard frames, poles, foundations, power infrastructure and utilities resulting in accumulative built volumes which impact visibility, natural light and sometimes accessibility. Creating media spots is an industry that will continue to boom and which may inspire the use of alternative design and technology solutions, for instance phosphorescent paints absorb heat during the day and glow at night potentially replacing outdoor electrical installations.

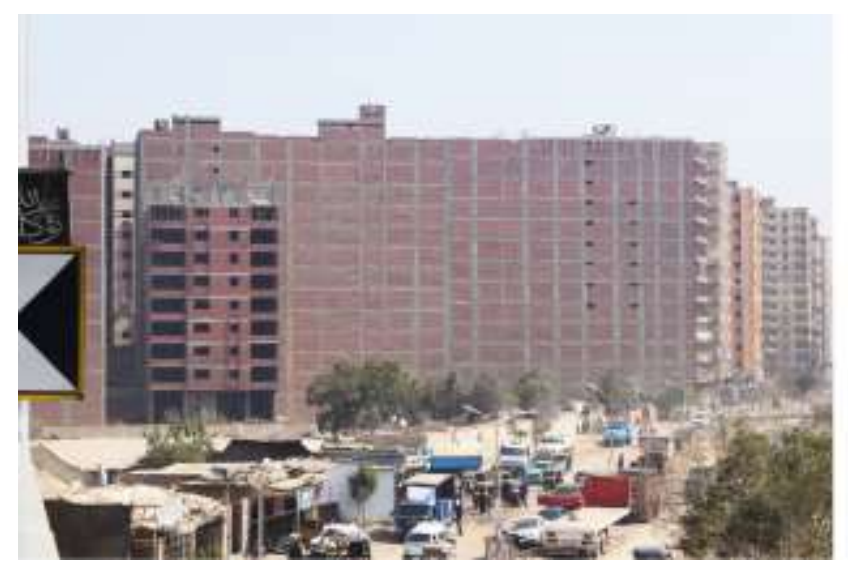

Figure 1 Vast ripe surfaces

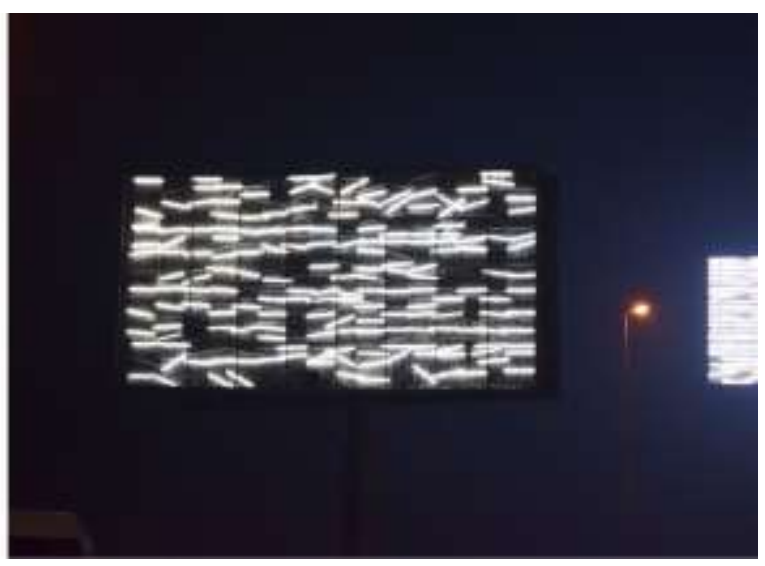

Figure 2 Unsustainable practices

\subsection{Construction industry}

On the other hand design and construction capacities are limited to the absence of law enforcement including unresponsiveness to informal construction activities and protection of heritage buildings. Repetitive interpretations and applications of design and building codes probably also limit the creative aspect and façade design qualities, one of the main reasons is that architecture and engineering are associated together when it comes to higher education on the national level lagging advanced tools and applied technical learning.

The visual and design quality standards continue to fade into the local market dilemmas especially in less fortunate neighborhoods between limited varieties of cheap and low quality products, undeveloped taste due to lack of exposure and of course the complex circumstances prioritizing other important life aspects leaving art and design as a luxury that not everyone can afford. 

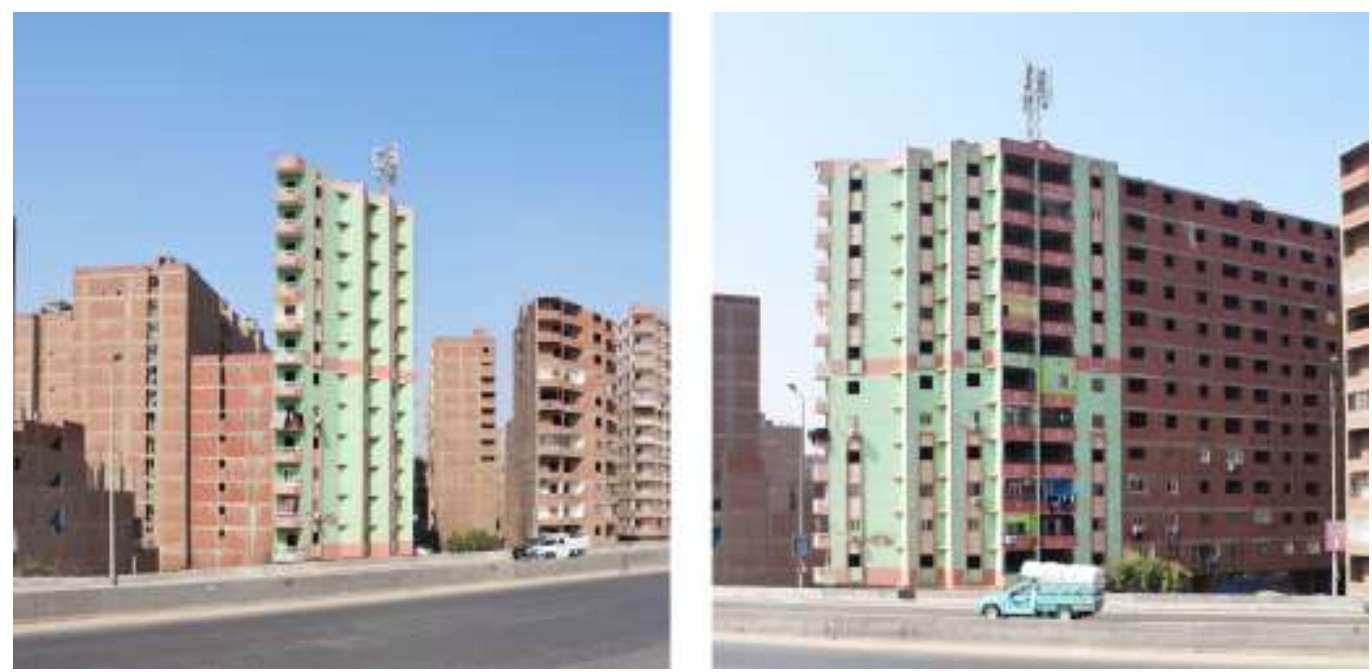

Figure 3 Partially finished building

\section{Urban observations}

\subsection{Façade colors and patterns}

There is a high preference for colors and ornamentation when it comes to exterior and interior designs, from the least fortunate neighborhoods to the most luxurious compounds people tend to express bright and cheerful designs reflected upon the real estate and built environment. Driving around the ring road in Greater Cairo for instance is a great inspiration for those interested in investigating the different façade typologies.
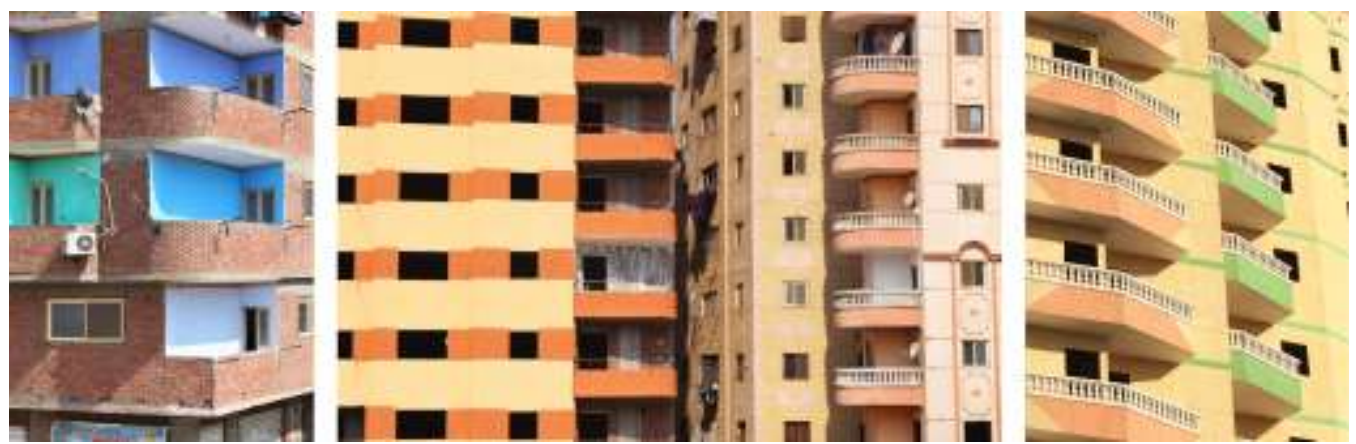

Figure 4 Preference for colors

In the countryside there are even more unique colors and patterns emphasizing the architectural elements and are inspired by nature, more colors and details usually demonstrate a higher social and wealth status.
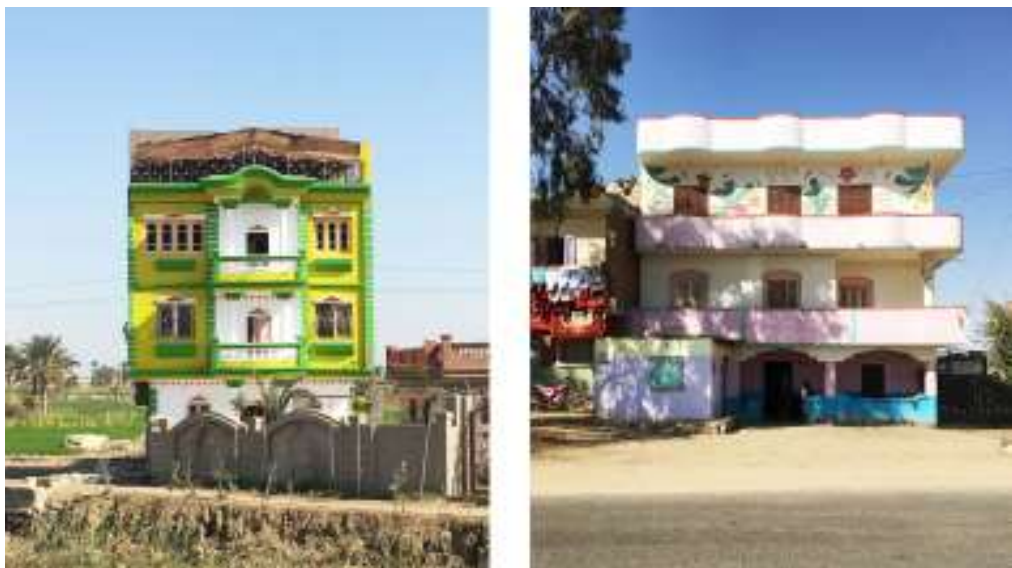

Figure 5 Faiyum Governorate 

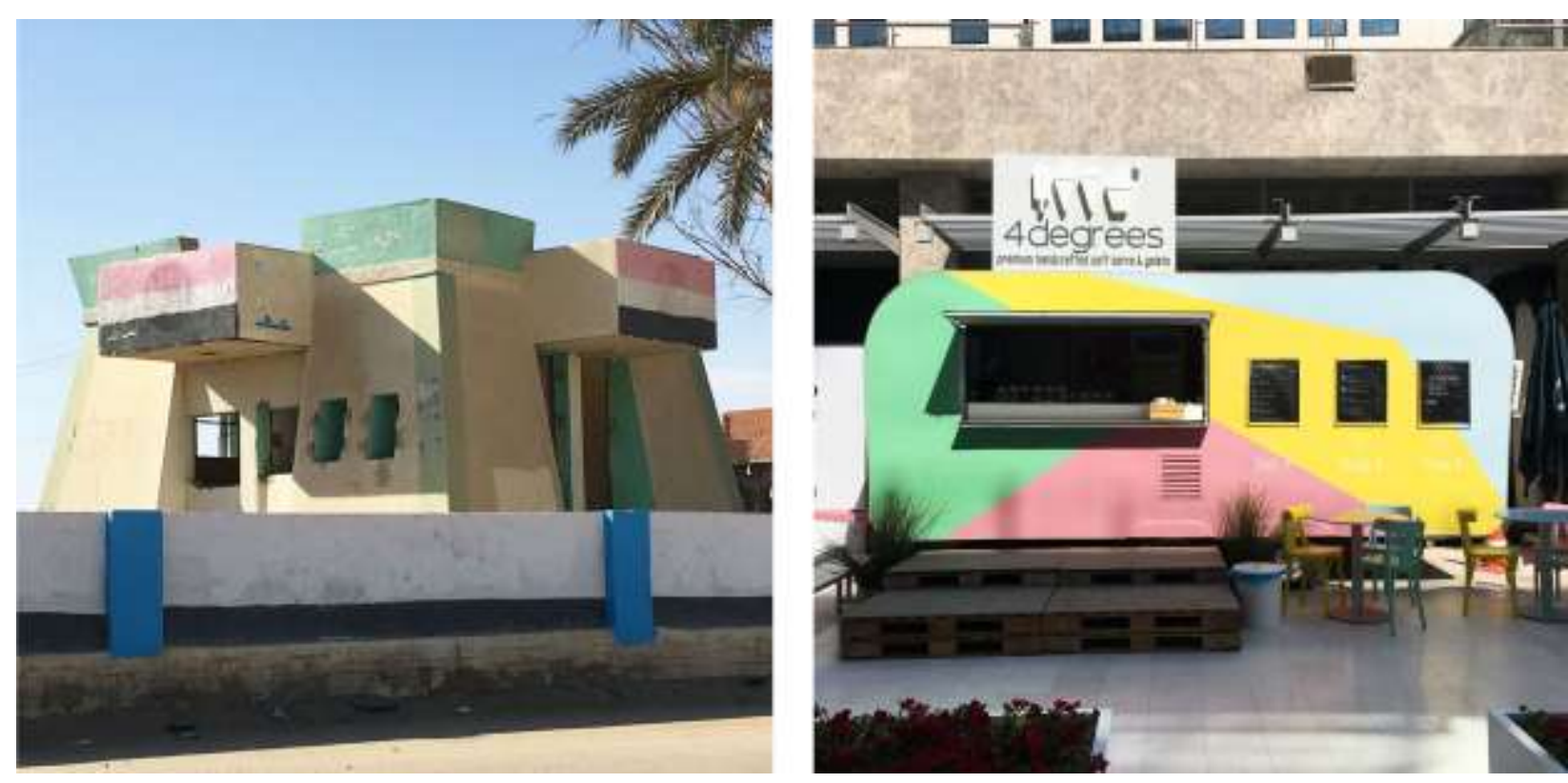

Figure 6 High contrasts yet similar elements

\subsection{Organized randomness}

Contractors among other suppliers may also advertise their products and services to the public most of which are successful by grabbing attention and conducting business.

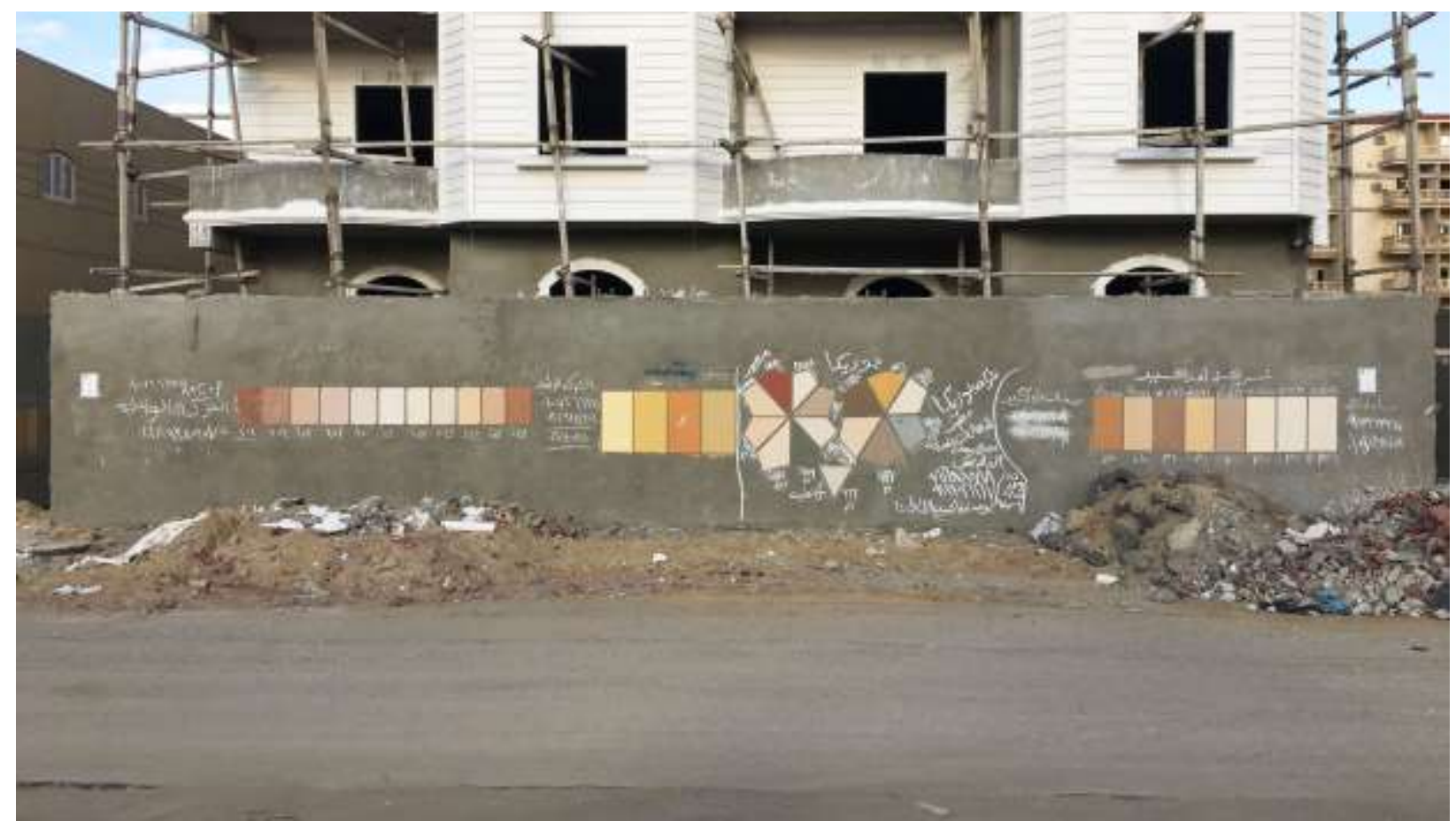

Figure 7 Color palettes 


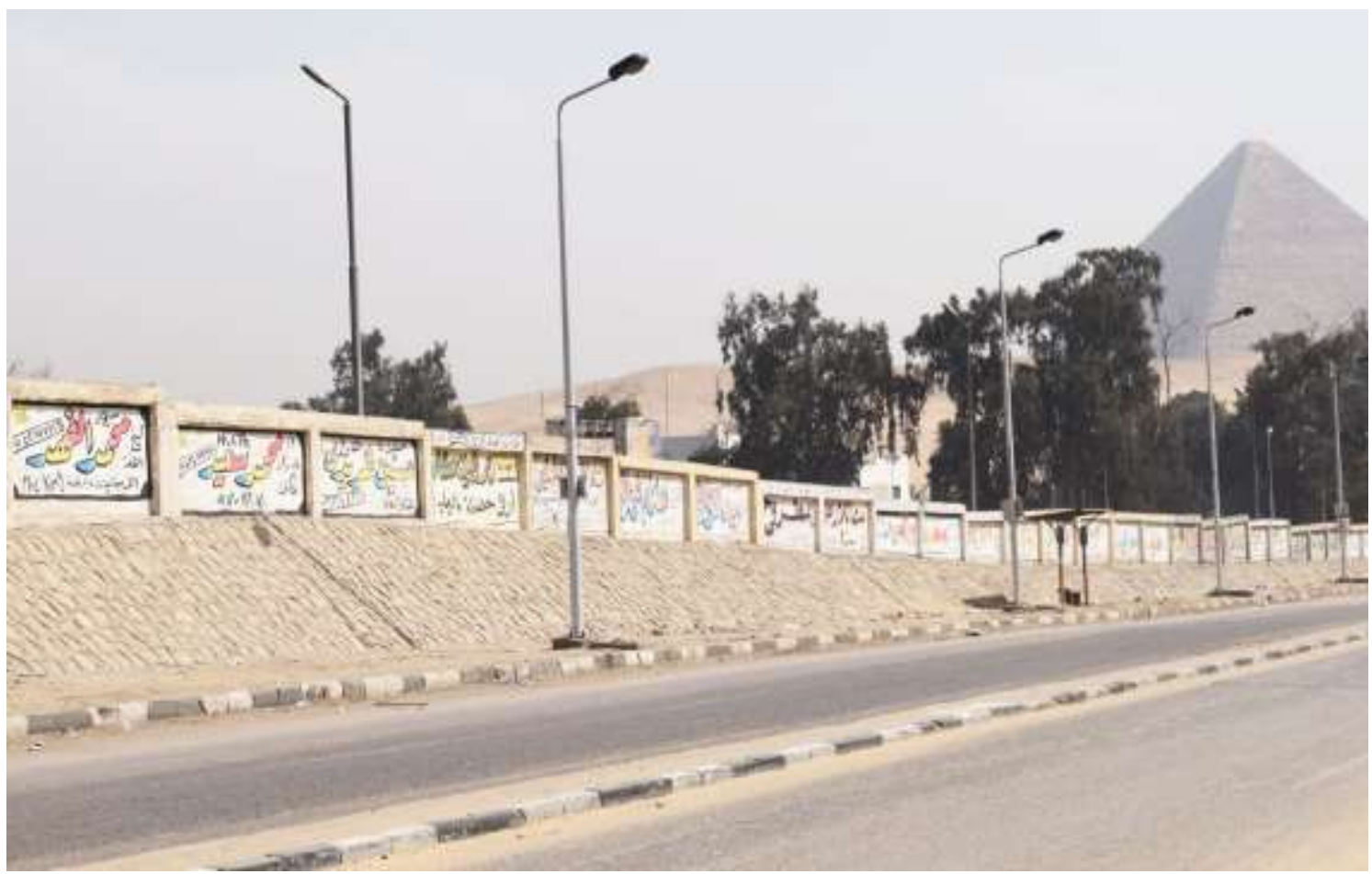

Figure 8 Wall as advertising panels

\section{Creative efforts and contributions}

Although the local art scene in Egypt is considered underdeveloped compared to the west, there is a huge potential to capitalize and build upon such rich local heritage and artistic production. As a matter of fact Egypt has the potential to become a center of excellence for art taking into consideration our expansive pool of talent in addition to the massive corporate marketing and construction budgets leaving behind surfaces and spaces ripe for transformative change.

\subsection{Commercial street art}

Cairo is overwhelming and one of the most live cities full of energy, wandering the streets one may realize an extremely dynamic and intensive commercial presence probably perceived as a kitsch advertising prototype in terms of colors, material and quality. Despite such immaturity there is a lot of potential in transforming those facades into an attractive street frontage with solid art and graphics providing direct and indirect advertising while preserving the local loud and decorative character observed as the colorful patches that we see everywhere around us on vehicles, walls and buildings.
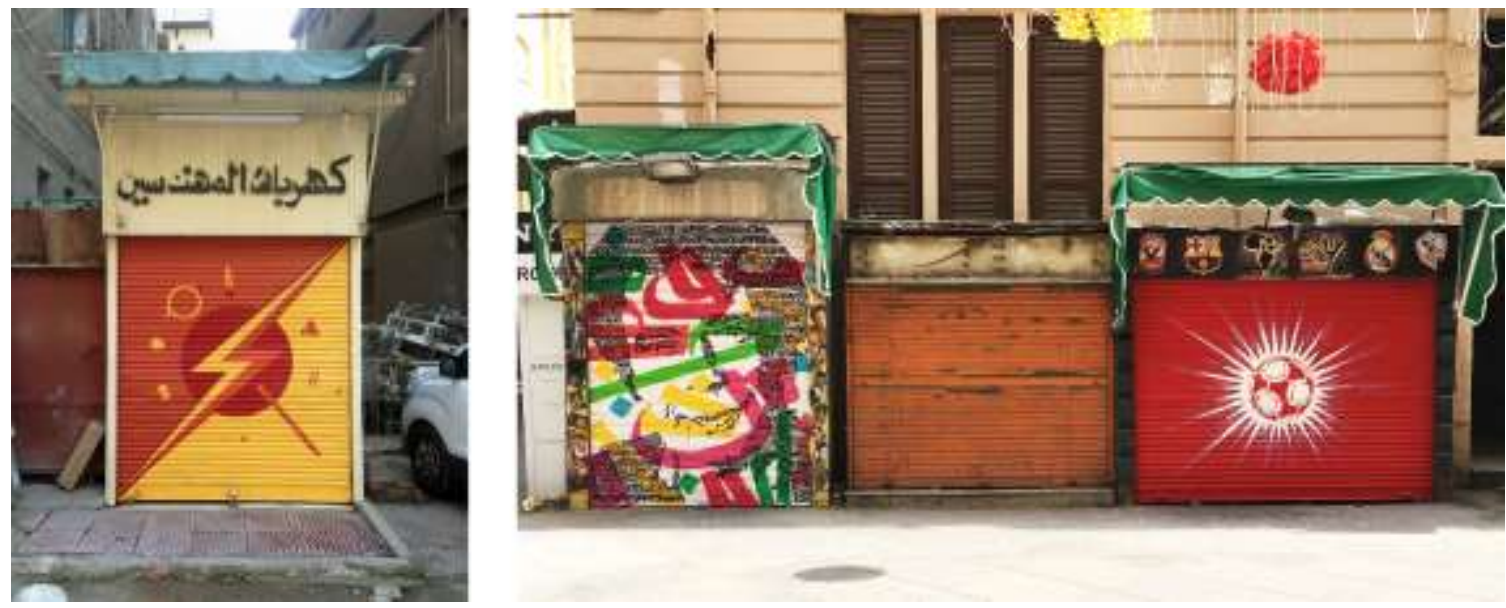

Figure 9 Examples of commercial street art 


\subsection{Decorative Concrete}

Examining the traditional and recurrent informal construction activities in Egypt one observes the repetitive typology of concrete grids and red bricks exposed all together as raw façades with minimum creative applications and interventions. Alternative approaches could result in a visual transformation when it comes to bricks and concrete, for instance using colored as well as decorative concrete casts.

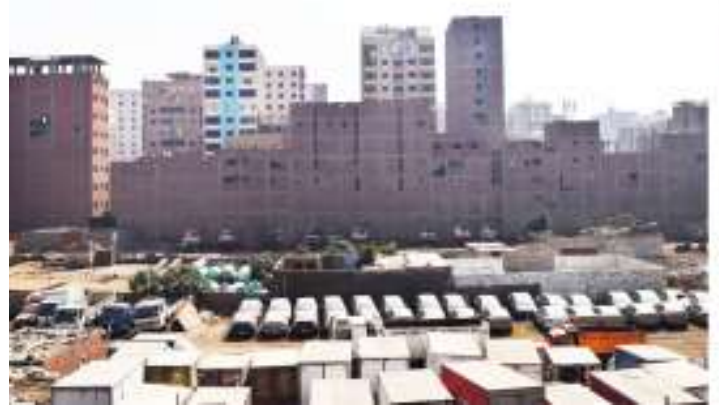

Figure 10 Informal housing skyline

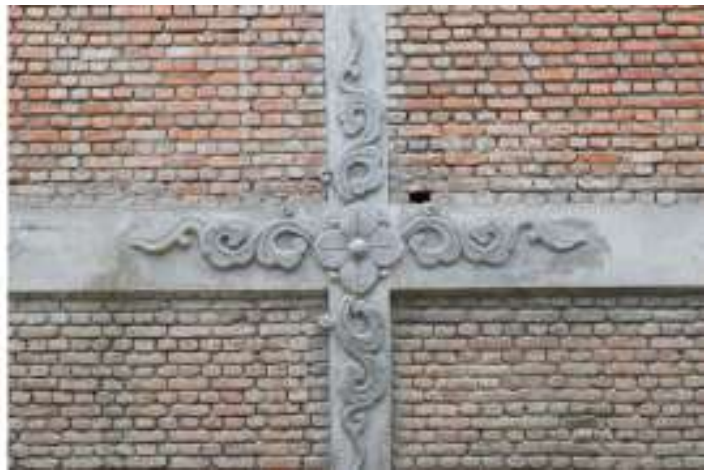

Figure 11 Example of decorative concrete cast

\subsection{Colorful bricks}

Several attempts occur for painting bricks as part of the façade treatment process resulting in very interesting and sometimes beautiful pixilated colorful surfaces, painting the bricks is indeed a practical and creative solution considering the additional costs related to alternative treatments including cladding materials among other applications. Most importantly this is happening organically and expanding on a national level.
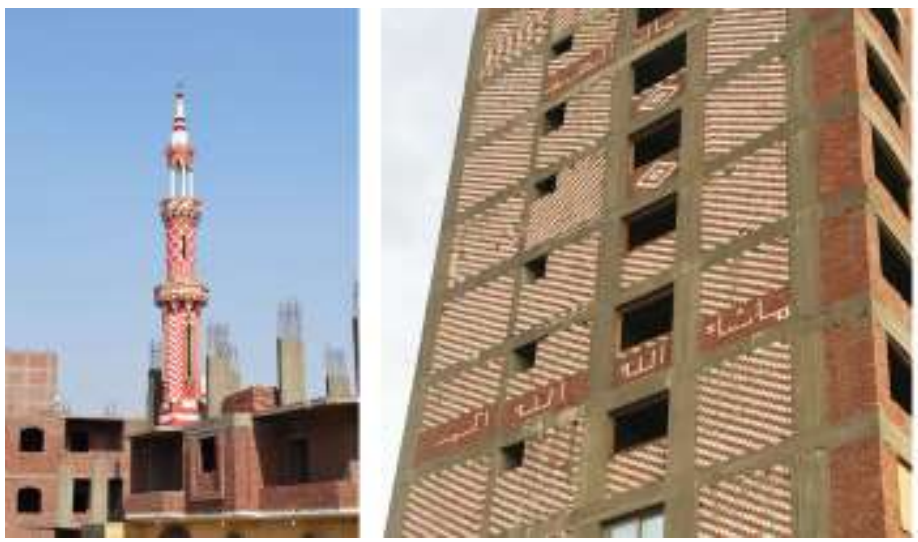

Figure 12 Examples of painted bricks
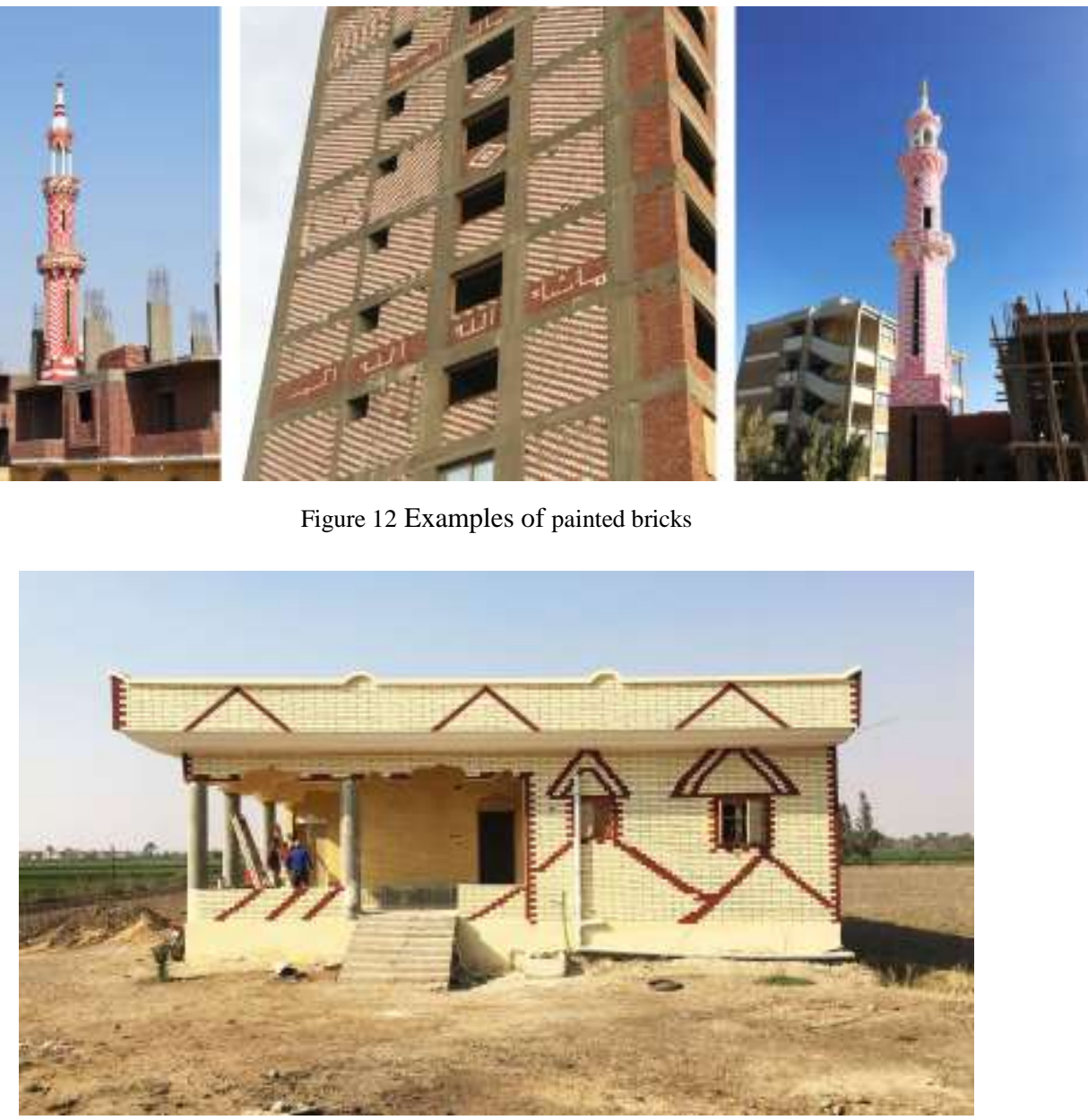

Figure 13 Example of painted bricks 


\subsection{Tinted bricks}

This may also inspire the idea of color dyeing bricks via separate production lines in brick factories by tinting the clay before or while being casted directly into the molds, a process that would facilitate, consolidate and optimize the design-build process.
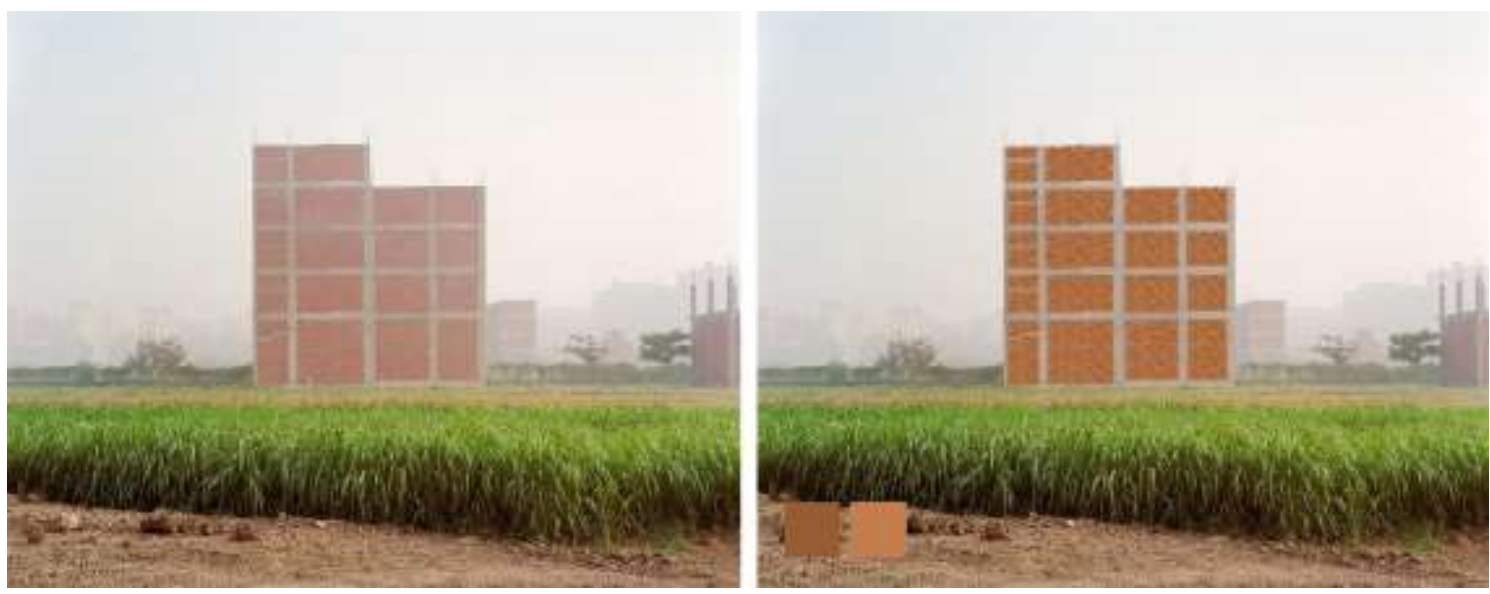

Figure 14 Concepts for tinted bricks
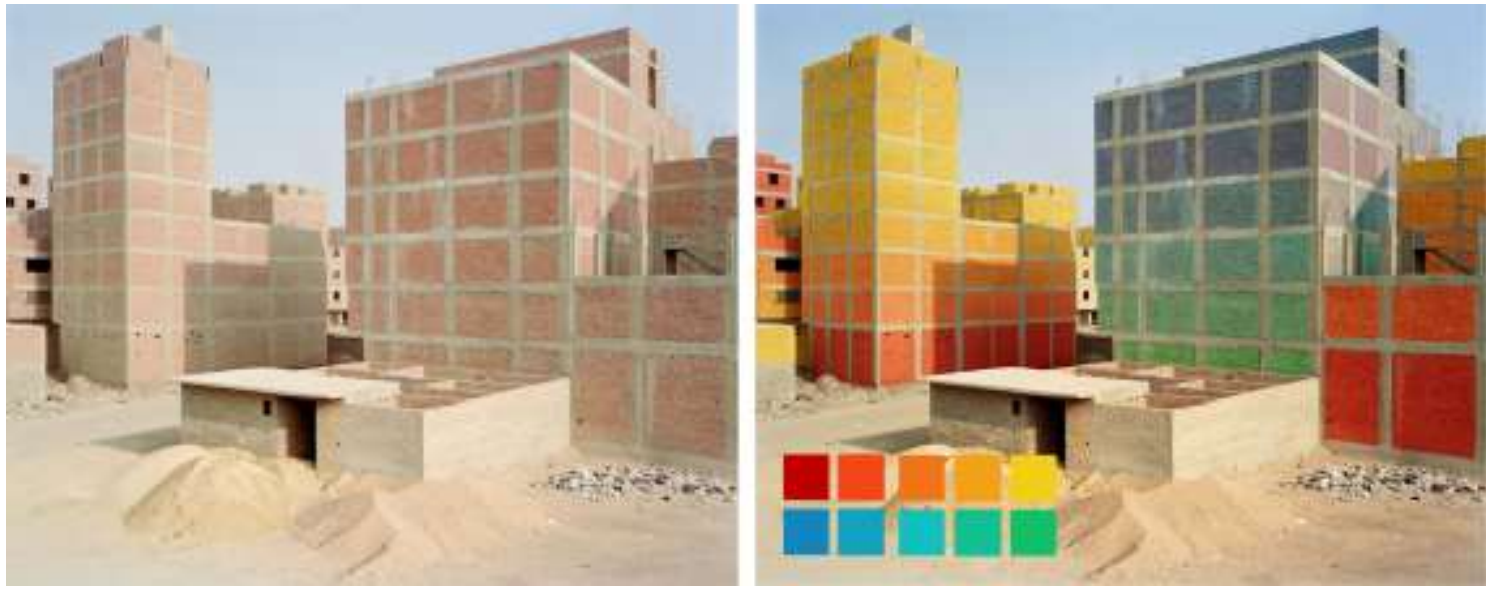

Figure 15 Concepts for tinted bricks

\section{Conclusion}

Egypt is and has always been very inspiring despite the lack or immaturity of a creative infrastructure and ecosystem including but not limited to art and design education, facilities and supplies however there is more need for competition, critical thinking and appreciation for arts and design. Unfortunately many craftsmen nowadays are giving up their inherited and acquired skill for other jobs that would tentatively better secure them financially but not necessarily satisfy their creative expression contributing towards discouragement of craftsmanship and unemployment.

The maturity and development of a sustainable creative and cultural infrastructure powered by cultural policies and practices is essential for the cultural and creative dynamics where creative cities attract creative people and without innovation we will continue to develop as a consumer based society, therefore $t$ is crucial to work with all stakeholders including the authorities and civil society with objectives that would aim to serve the best interests and gain a positive public opinion. 